Res Publica. Revista de Historia de las Ideas Políticas ISSN: 1576-4184

http://dx.doi.org/10.5209/RPUB.60855

\title{
El Pablo de Žižek
}

\author{
Eugenio Muinelo Paz ${ }^{1}$
}

Recibido: 04/03/2017 / Aceptado: 11/12/2017

Resumen. Slavoj Žižek ha pretendido identificar el núcleo no ideologizado del cristianismo y su pertinencia como instancia crítica del orden en que se sustenta el capitalismo global. En primer lugar, como clarificación conceptual preliminar, querríamos exponer el modo en que Žižek hace derivar la matriz de su idea del materialismo dialéctico a partir del dogma trinitario de la Encarnación, que tiene su primera formulación en la doctrina paulina de la kénosis de Dios. Según su lectura de Schelling y Hegel, no se puede captar la génesis de la subversión materialista del discurso filosófico sin atender a cómo se elaboró en el idealismo alemán la noción de lo Absoluto y de su decisión-escisión en tanto que autoenajenación de Dios. Por último, intentaremos mostrar cómo sólo una praxis que asuma las aporías que se siguen de ello puede alcanzar una universalidad no abstracta y que tal fue la praxis que intentó perfilar Pablo en la constitución de la Iglesia.

Palabras clave: materialismo dialéctico; kénosis; universalidad; no-identidad.

\section{[en] Žižek's Paul}

Abstract. Slavoj Žižek has pretended to identify the non-ideologized core of Christianity in order to find a point of departure to criticize global capitalism. First of all, as conceptual clarification, we want to expose how Žižek let his idea of dialectical materialism come out of trinitarian dogma of Encarnation, which was first formulated through St. Paul's doctrine of God's kénosis. According to his lecture of Schelling and Hegel, the materialist subversion of philosophical discourse can't be understood without paying attention to how the notion of Absolute was elaborated in German Idealism as decision-scission and self-alienation of God. Lastly, we will try to show why only a praxis that has faced the predicaments which follow from it is able to obtain a non-abstract universality. Such a praxis was the one which Paul tried to shape at the constitution of the Church.

Keywords: Dialectical materialism; kenosis; Universality; Non-identity.

Sumario: 1. La genealogía idealista del materialismo dialéctico. 2. La constitución onto-teo-ideológica del Capital. 3. La revelación traumática del amor.

Cómo citar: Muinelo Paz, E. (2018). El Pablo de Žižek, en Res publica 21.2, 353-368.

\footnotetext{
1 Universidad Complutense de Madrid emuinelopaz@gmail.com
} 


\section{La genealogía idealista del materialismo dialéctico}

La ocupación de Slavoj Žižek con el idealismo alemán busca arrojar luz sobre la relación viva que éste mantiene con el surgimiento plenamente consciente del materialismo dialéctico. En la mayoría de los estudios sobre la posteridad espiritual de Hegel se enfatiza el aspecto de la ruptura con el idealismo mediante una inversión de la dialéctica.

¿Por qué poner en cuestión la validez de tal propuesta hermenéutica? Según Žižek, porque pasa por alto que la explosión del idealismo se produjo desde su propio interior. Siendo esto así, no habría que hablar tanto de Marx, Kierkegaard y Nietzsche como del último Schelling y, contra un lugar común bien asentado en la doxa filosófica, del propio Hegel. Con estos empieza la destrucción interna del idealismo, de modo que ver en Schelling al gran adalid del irracionalismo que desembocará en Hitler, como quiso Lukács, es una completa aberración histórico-conceptual. En esto, como en tantos otros aspectos, Lukács se hallaba en divergente acuerdo con Martin Heidegger, que hacía depender toda la relevancia histórica del pensamiento schellinguiano de la irrupción del Wollen ist Urseyn de las Investigaciones filosóficas sobre la esencia de la libertad humana, definitorio de la subjetividad moderna qua voluntad de poder según se consumará en Nietzsche.

No perderemos demasiado tiempo en exponer la visión convencional de la relación de Schelling con Hegel (crítica del panlogismo, apertura a lo irracional de la decisión, etc.), pues de lo que se tratará en lo que sigue es de detectar la complementariedad profunda en que se encuentran y de extraer de ella los lineamientos teóricos básicos de lo que Žižek entiende por materialismo dialéctico. Como se sabe, momento privilegiado en la constitución del materialismo es para Žižek la escritura, inacabada como todo genuino pensamiento materialista de Lucrecio a Lacan, de las Weltalter schellinguianas. Su problema, como el de la Ciencia de la Lógica, es la modalidad de Dios antes de la Creación y su fenomenalización "en el principio". El Logos que está "en el principio" es precisamente lo que da cuenta de la escisión interna del Absoluto que le lleva a salir fuera de sí, a excederse. Sin el Logos no tenemos más que el ritornello infinito de la pulsión de repetición: ptah, dharma, ananké, fatum..., al cual Schelling llama, en el escrito sobre la libertad, Grund, fundamento y origen de todas las cosas. Y la libertad, ese desdoblamiento de Dios en sí mismo que no es otra cosa que el Logos, nace en consecuencia de una ausencia de fundamento (la experiencia psiconalítica del no-todo), de un Ungrund, de una disociación insuturable del Absoluto consigo mismo, de una Entscheidung del Absoluto, de una decisión.

En su fenomenología de la acción libre, Schelling se ve impelido a postular, para vadear los atolladeros en que quedaron atrapados Lutero, Leibniz y Kant, nada menos que la propia noción del inconsciente. La desestabilización en que consiste la existencia humana tiene que ver con su capacidad de revelar el Grund de todo ser como estando, si no extra Deum, sí al menos praeter Deum. De tal capacidad brota la facultad positiva para el mal que define la esencia de la libertad. El mal, que desde san Agustín es un estar separado de Dios por el amor sui, en psicoanálisis podemos reformularlo en términos de narcisismo primario de la imagen especular, que sólo la vía de la sublimación (el "espíritu", desde Pablo al idealismo alemán) puede hacer penetrar en lo real: 
El principio surgido a partir del fundamento de la naturaleza por el que el hombre está separado de Dios, es su mismidad (Selbstheit), que, sin embargo, a través de su unión con el principio ideal, se vuelve espíritu... [la mismidad que] es voluntad que se contempla a sí misma en la libertad total y ya no es instrumento de la voluntad universal que crea en la naturaleza, sino que está por encima y fuera de toda naturaleza ${ }^{2}$.

Esto es: preludiando las tesis de toda la antropología filosófica de Jakob Johann von Uexküll a Hans Blumenberg pasando por Helmuth Plessner, sólo el hombre puede decidirse (escindirse del fundamento) debido su posición excéntrica con respecto a su mundo entorno, que le permite tomarse a sí mismo por su propio centro, haciéndosele visible su propia visibilidad. Y lo psicoanalíticamente relevante del asunto es que tal decisión por la excentricidad ha tenido siempre ya lugar. Schelling describe este carácter de la decisión como una incursión de la eternidad en el tiempo estructuralmente análoga a la formación del síntoma. El haber-tenido-siempre-ya-lugar de la decisión provoca la petrificación del acto radicalmente libre que funda la conciencia. Así, como síntoma, se hace independiente y le opone resistencia, lo cual no quiere decir que por un largo rodeo no se pueda acceder a esa dimensión constitutiva de la conciencia, el Ello freudiano que siempre puede, si se emprende la ardua tarea analítica, devenir Yo.

Desde luego, este acto libre que se convierte en necesidad, no puede producirse en la conciencia, en la medida en que ésta es mera autoaprehensión y ello sólo de modo ideal, puesto que es él el que la precede, al igual que el acto a la esencia, y el que la constituye; pero no por ello es un acto del que no le haya quedado en absoluto ninguna conciencia al hombre... ${ }^{3}$.

No cuesta concebir, a partir de ese párrafo, la homología estructural entre síntoma e ideología. Esta noción materialista de sujeto que está aquí pergeñando Schelling, ¿acaso no recuerda al aserto del 18 Brumario sobre los hombres que hacen la historia en circunstancias no elegidas por ellos? ¿O a las descripciones de la ideología como el hacerse obvias, naturales y fatales de condiciones bien modificables que responden a relaciones de poder? ¿Y acaso no es el síntoma una tal formación, en apariencia irresistible, mas en verdad expugnable merced al hilo rojo que une el Yo al Ello?

Anticipemos ya algo que Schelling trata en las Investigaciones y que será central en lo sucesivo: el amor es la fuerza suprema y estrictamente universal en virtud de la cual pueda recobrarse la conciencia de ese originario acto libre de la escisión, posibilitando su ulterior unificación en una más completa unidad. La absoluta indiferencia del Ungrund con respecto a los opuestos de él derivados es prefiguración de la escatológica conmixtión en que, según el versículo paulino, será "todo en todo" (I Cor, 15, 28).

Transitemos ahora a las Weltalter, que no son sino una transferencia del problema de la decisión a la personalidad divina: la decisión es, pues, el acto eterno, inmemorial e inconsciente, que ha dejado out of joint los elementos centrípetos del pasado

F. W. J. Schelling, Investigaciones filosóficas sobre la esencia de la libertad humana, Barcelona, Anthropos, 2000, p. 179.

3 Ibidem, p. 233. 
antemundano. Pasado que, enorme paradoja, nunca fue presente, que es un pasado eterno y que es constitutivo del tiempo como tal. La filosofía, desde sus aurorales balbuceos jónicos, ha partido del presupuesto ontoteológico de que el tiempo del mundo presente es el único que hay, ignorando la pluralidad de los tiempos que sólo se puede atisbar desde un a-tópico afuera del presente, afuera del mundo. Abrir la brecha del tiempo en el cosmos compacto de la ontoteología (de ahí la temprana admiración de Heidegger por Schelling) fue sin duda uno de los desiderata más persistentes en el prolongado itinerario de Schelling. Así, sin tal desajuste entre tiempo y mundo, no se entiende que haya algo así como un pasado y un futuro:

Aunque se hubiera confirmado en todos los sentidos la vieja frase de que en el mundo no sucede nada nuevo, [...] de ahí sólo se seguiría que el mundo no tiene en sí ni pasado ni futuro, que todo lo que en él ha sucedido desde el comienzo y lo que sucederá hasta el final pertenece a un único gran tiempo; que el auténtico pasado, el pasado sin más, es el premundano; que el auténtico futuro, el futuro sin más, es el postmundano, y de este modo se nos desplegaría un sistema de los tiempos del que el sistema del tiempo humano sólo sería una copia, una repetición en un círculo más estrecho ${ }^{4}$.

Estamos, pues, ante un sistema de los tiempos generado por la multiformidad de la experiencia y que hace estallar toda topología u-crónica del presente. Como apunta Žižek,

el Absoluto "abre el tiempo", "reprime" el movimiento rotatorio en el pasado, con vistas a liberarse de su antagonismo interno, que amenaza con arrastrarlo al abismo de la locura. [...] [El tiempo para Schelling es] el punto de decisión sin fundamento por medio del cual una criatura libre (el hombre) fractura, suspende la cadena temporal de razones y, por así decirlo, conecta directamente con el Ungrund del Absoluto 5 .

Mas, ¿cómo justificar lo que dijimos ser el propósito de estas consideraciones preliminares, esto es, indagar en la genealogía del materialismo dialéctico? ¿Cómo conectar la lectura aquí presentada de la fenomenología schellinguiana de la acción libre, tanto en el Absoluto como en lo finito, con una posible noción materialista del sujeto, como la que ha de ser para Žižek la que sustente todo proyecto de praxis universal? Con sus propias palabras:

Por muy paradójico que pueda sonar, con esta específica noción de la libertad en tanto que libre relación del sujeto con su existencia y noción, Schelling fue el primero en delinear los contornos de una noción materialista del sujeto. En la versión

\footnotetext{
F. W. J. Schelling, Las edades del mundo, Madrid, Akal, 2002, pp. 125-126.

S. Žižek, The indivisible remainder, Londres, Verso, 2007, p. 31. Cabría evocar aquí cómo Negri y Hardt emparentan la exclusividad del presente con la ontología del Imperio: "El imperio agota el tiempo histórico, suspende la historia y convoca al pasado y al futuro dentro de su propio orden ético. Para decirlo de otro modo: el imperio presenta su orden como permanente, eterno y necesario" (cf. M. Hardt y T. Negri, Imperio, Barcelona, Paidós, 2005 , p. 31). A esta como omnipresencia imperial, podría confrontarse la temporalidad plural democrática, nombrando para ello, entre otros, a Walter Benjamin y su redención de la historia como enmienda del pasado, o a Chesterton y su idea de una "democracia de la muerte".
} 
standard (idealista y materialista) de la oposición filosófica de sujeto y objeto, la materialidad está siempre del lado del objeto: el objeto es denso, impenetrable e inerte, mientras que el sujeto se erige en la transparencia del Pensamiento a sí mismo; dentro de este horizonte, el único modo de afirmar una posición materialista es mediante el intento de demostrar cómo el sujeto es siempre-ya un objeto ${ }^{6}$.

Como se sabe, para Žižek habría que insertar también la sustancia-sujeto hegeliana dentro del marco de la afirmación materialista. El saber absoluto no sería, desde su punto de vista, la renuncia a las tensiones propias de una noción materialista del sujeto, sino el estadio final al que conduce la exasperación extrema de las mismas (la lucha a muerte por el reconocimiento, etc.). Dado que Hegel ocupa un lugar nada desdeñable en los estudios sobre Žižek, sería ocioso abundar aquí en la cuestión.

\section{La constitución onto-teo-ideológica del Capital}

Hemos llegado de la mano de Schelling a una circunscripción materialista de la noción de sujeto, según la cual éste está siempre ya implicado en la contextura objetiva de su praxis, generando así siempre un resquicio ineliminable de opacidad conceptual. Ello supone un cuestionamiento radical de la disociación epistemológica moderna, que, si secundamos el diagnóstico de Heidegger (cosa que haremos en lo sucesivo con no pocas salvedades), hay que retrotraer más allá del momento cartesiano, hasta la reducción entificante de la verdad a corrección y correspondencia con la Norma inteligible efectuada por Platón.

El entretejimiento materialista de sujeto y objeto se dirige precisamente contra tal ecuación ontoteológica, basada en el carácter divino e inmutable del orden del ser. El materialismo dialéctico recusa esa unilateralidad por mor de la cual el sujeto ha de plegarse al objeto. Contra la ontoteología que, por mucho que le pese a Heidegger, se inaugura con el dictum parmenídeo sobre la identidad de ser y pensar, el núcleo vivo del materialismo dialéctico consiste en mostrar, en la estela de Adorno, "cómo emerge, desde el orden chato del ser positivo, la verdadera brecha entre pensamiento y ser, la negatividad del pensamiento"7.

Tal es la brecha de paralaje que multiplica los planos sobre un mismo objeto, ofreciendo una pluralidad de perspectivas inasequible a la mirada temática unívoca tanto del idealismo convencional como del así llamado materialismo histórico, ambos lastrados por el mismo déficit narcisista de "real". No consiguen penetrar en lo real porque permanecen anclados en la justificación ontoteológica del vigente estado de cosas. El orden del ser es inmodificable, porque divino: tal es la estructura, por muy distorsionada que se nos transmita, de toda argumentación ontoteológica, presta siempre a camuflar su renuencia a la carga libidinal de un objeto exterior a sí mismo mediante la reproducción siempre ampliada de la imagen especular y la seguridad que infunde el creerse ínsito en un infalible sistema de inmunidad.

Peter Sloterdijk, en su vasto proyecto de una filosofía de la globalización, desentraña atinadamente este ambiguo aspecto del cierre del proceso global del capitalismo: lleva a su consumación la tendencia a la unitotalidad inherente a la ontología

S. Žižek, The indivisible remainder, op. cit., p. 71.

S. Žižek, Visión de paralaje, Buenos Aires, FCE, 2006, p. 15. 
como tal. La homogeneidad esférica del ser, la inmóvil eukýklos sphaíres de Parménides, extendió "el evangelio de la inclusión total". La metafísica de la inmunidad sostiene la garantía de que todo está "dentro", de que no hay ni puede haber irrupción alguna que perturbe nuestro cobertizo esferológico. Desde otra perspectiva abordó la misma cuestión el injustamente olvidado Alfred Sohn-Rethel al detectar en el to eon de Parménides el corolario conceptual de la abstracción-mercancía condensada en la acuñación monetaria, que se dio por vez primera en torno al s. VII a. C. en la zona jónica del Egeo, en Lidia y en Frigia. Se consumó así la escisión, provocada por la relación de clase, entre "trabajo espiritual" y "trabajo corporal": inalterabilidad, omniespacialidad, homogeneidad, uniformidad, etc., son todas ellas cualidades que descubre el trabajador espiritual por antonomasia, el filósofo. La inercia estática común al pensamiento antiguo se debe a una suerte de "solipsismo práctico", en el que hacía pie, según Sohn-Rethel, la "síntesis social” de la Grecia Antigua (recuérdese nuestra asociación, más arriba, de ontoteología y narcisismo), del que nació la propia noción de mercancía, de valor de cambio, de propiedad privada etc., y que Marx describió en El capital en su forma más acabada como una relación de extrañeza recíproca (wechselseitige Fremdheit). La abstracción-intercambio se independiza de la realidad empírica por mor de la reificación de las relaciones sociales, sin dejar rastro en la conciencia individual de su carácter histórico. De este modo, el to eon no sería sino el "material del que debería estar hecho el dinero", la garantía, que jamás podrá ser conculcada (su no-existencia no puede pensarse), de que el orden de la abstracción-mercancía subsiste por necesidad natural.

Volviendo a Sloterdijk, podría argüirse que trata con demasiada premura el tránsito de la esferología precristiana a un supuesto sistema teológico de inmunidad jerárquicamente estructurado por el aristotelismo. De la mano de Žižek, intentaremos hacer ver precisamente lo inusitadamente poco inmunológica que fue la experiencia cristiana originaria, tan hundida como estaba en aquella incertidumbre veterotestamentaria de ser un "peregrino en la tierra", como se dice en el Salmo y repetirá Pablo.

En la metafórica de la esfera se condensan, pues, los grandes motivos ontoteológicos de la autorreferencialidad y de la inmunización. Podemos conectarla así con la exposición schmittiana del complejo teológico-político en tanto que definitorio de la soberanía moderna: la aseidad que, en virtud del estado de excepción, el soberano se arroga con respecto al orden constituido le confiere la ocasión de crear un nuevo orden, cuya justificación no puede ser otra que su propia decisión. A sabiendas de estar aquí simplificando la escurridiza conceptualidad schmittiana (habría que atender para matizar su decisionismo a cierto horizonte de normatividad consuetidinario-existencial que presenta la Teoría de la Constitución), la disyuntiva es, sin embargo, clara y palmaria: o bien lo político como totalidad tiene su razón de ser en sí mismo, emulando la causa sui de la metafísica, o bien ha de postularse su excentricidad y ha de reconocerse la necesidad de que integre en sí mismo un resto irreductible de alteridad. Nos gustaría demorarnos en cómo este filosofema, pese a lo dúctil que ha sido a lecturas subversivas como las del propio Žižek o Chantal Mouffe, se corresponde estructuralmente con la premisa ontoteológica de la filosofía antigua, y en cómo fue la erosión de la exterioridad cristiana con respecto a los pode-

P. Sloterdijk, Esferas II. Globos, Madrid, Siruela, 2004, p. 107.

A. Sohn-Rethel, Trabajo manual y trabajo intelectual, Barcelona, Ediciones 21, 1979, p. 73. 
res temporales, siempre hostil a la ontoteología y tendiente a la desfundamentación de lo político, la que propició su restitución en el umbral moderno del humanismo nacional secularizante, de lo cual trató Derrida en un artículo poco conocido. Pero requeriría demasiado tiempo y nos desviaría demasiado del punto al que queremos arribar: la lectura de Pablo por Žižek.

Un buen trabajo en que poder constatar esta incompatibilidad entre el planteamiento ontoteológico y una praxis universal sería el libro de Alain Badiou sobre El ser y el acontecimiento, cuyo título indica, más que una conjunción, una disyunción exclusiva. Pues bien, como Žižek no se cansa de reiterar, fue Badiou precisamente uno de los que con más ahínco insistió en el "acontecimiento" paulino y en su carácter paradigmático. Pablo habría sido el teórico anti-filosófico (recuérdense las sonoras carcajadas de los atenienses en Hechos) por excelencia de las condiciones formales del procedimiento de acontecimiento-verdad y fidelidad infatigable al mismo. La diseminación de la verdad en una perspectiva universal, concerniente a cada sujeto, es sin duda un acontecimiento (y como tal, impredecible, improbable, gratuito, sin quedar al albur de cada cual) cuya descripción emprendió Pablo por vez primera y con eficacia pasmosa. Antes de profundizar en ella, retengamos un párrafo de Žižek que ilustra bien la cuestión:

Aquí reside el mensaje del cristianismo: la positividad del Ser, el Orden del cosmos regulado por sus Leyes, que es el dominio de la finitud y de la mortalidad (desde el punto de vista del cosmos, de la totalidad del Ser positivo, no somos sino seres particulares determinados por nuestro lugar específico en el orden global -la Ley es en última instancia otro nombre para el Orden de la Justicia cósmica, que nos coloca a cada uno en su propio lugar), no es "todo lo que hay"; hay otra dimensión, la dimensión de la Verdadera Vida en el Amor, accesible a todos nosotros por la Divina Gracia, de modo que podamos participar en ella. La Revelación Cristiana es así un ejemplo (aunque probablemente el ejemplo) de cómo nosotros, seres humanos, no estamos constreñidos a la positividad del $\mathrm{Ser}^{10}$.

No sería descabellado esbozar aquí una correlación profunda entre la subversión paulina del sujeto y la crítica de la ideología de Marx a Lukács, Sohn-Rethel y Franz Borkenau: la plenitud ontológica (en el estadio de la modernidad capitalista por ellos escudriñado, la "reificación") no abarca el conjunto de lo real. Hay un resto siempre, el "no-todo" insubsumible desde el que se quiebra el velo ideológico de la aparente inmutabilidad del orden positivo y se desenmascara la contingencia de la que de facto ha emergido tal orden ontológico positivo: "En este preciso sentido, toda ontología es «política»: fundada en un inconfesado acto de decisión subjetivo y contingente" 11 .

De ahí el énfasis de Žižek en subrayar cuán decisivamente política era la economía política burguesa del laissez faire a la que se enfrentó críticamente Marx. La práctica desaparición del concepto de ideología en el tránsito a los Grundrisse y al Capital no ha de inducirnos al error de juzgar que su relevancia se hubiese difuminado. Todo lo contrario: se trataba para Marx de captarla in fieri, en su papel imprescindible en el engranaje del Capital. Véase, por ejemplo, la certera fenomenología de

S. Žižek, The ticklish subject, Londres, Verso, 2008, p. 170.

$11 \quad$ Ibidem, p. 185. 
la circulación como reducción a valor de cambio, que hay que leer indefectiblemente en clave de crítica de la ideología como coagulación e inmunización de un (quizá el) modo específico de (la) dominación:

Aunque ahora el conjunto de este movimiento se presente como proceso social, $\mathrm{y}$ aunque los distintos momentos de este movimiento provienen de la voluntad consciente y de los fines particulares de los individuos, sin embargo, la totalidad del proceso se presenta como un nexo objetivo que nace naturalmente, que es ciertamente el resultado de la interacción recíproca de los individuos conscientes, pero no está presente en su conciencia, ni, como totalidad, es subsumido en ella. $\mathrm{Su}$ misma colisión recíproca produce un poder social ajeno situado por encima de ellos; su acción es recíproca como un proceso y una fuerza independientes de ellos. La circulación [...] es la primera forma, en la que no sólo la relación social [...] se presenta como algo independiente de los individuos, sino el conjunto del propio movimiento social. La relación social de los individuos entre sí como poder sobre los individuos, que se ha vuelto independiente [...], es un resultado necesario del hecho de que el punto de partida no es el individuo social libre ${ }^{12}$.

Podrían extraerse de este solo párrafo los elementos para una crítica de la teología política del Capital, pues no en vano es la verticalidad excepcional de la soberanía uno de los nervios de la primera entrega de la Teología política, así como de El cuerpo del amor de Norman O. Brown, en donde se nos muestra el carácter político de la erección, siendo la soberanía como la erección (estado de excepción) del cuerpo político. Aquí Marx debela la ilusión de naturalidad (de legitimidad, podríamos decir weberianamente, por muy plausible que sea su acatamiento) de todo poder ejercido "sobre", de toda hegemonización parcial del significante vacío. Huelga decir que Schmitt, buen lector de las patéticas páginas de Walter Benjamin sobre la melancolía del soberano barroco (contemporáneo, por cierto, de la consolidación del sistema-mundo capitalista), era bien consciente del porvenir de esa ilusión. La soledad del poderoso que ya de nada tiene que dar cuenta (desintegración superestructural, disolución de vínculos y relaciones de dependencia personal tradicionales, etc.) sólo podía mitigarse con el recurso a ese decisionismo expresionista autofundante que Schmitt creyó poder identificar, harto anacrónicamente, en los más antiguos dogmas de la teología cristiana, nada menos que en la Trinidad.

Žižek y Laclau coinciden en que la operación política por excelencia sea la suturación ideológico-hegemónica de lo parcial con lo Universal, merced a la cual el orden del Capital se muestra como preter- o meta-político, sostenido por fundamentos objetivos que responden a la naturaleza de las cosas. Schmitt se quedó sólo con una cara de la moneda marxiana: toda despolitización esconde siempre una repolitización correspondiente que la contrarresta. Se hace urgente combatir la imagen de un inocuo Orden Global post-político y post-ideológico que pulula por varios diagnósticos del presente. El círculo del capitalismo tardío en trances de cerrarse es vicioso porque obtura la autoconciencia del "individuo social libre" del pasaje de los Grundrisse recién citado. Demasiado bien sabemos que la fachada multiculturalista y tolerante no es sino expresión clamorosa de la congénita maleabilidad de la lógica

12 K. Marx, Elementos fundamentales para la crítica de la economía política (Grundrisse), v. I, Madrid, Siglo XXI, 1972, p. 131. 
del Capital llegado al punto en que ya no se encuentra ninguna tradición concreta que le haga frente. Cuando ninguna importa, se toleran todas; ése es el ardid ideológico del capitalismo tardío con su universalidad abstracta y permeable a todo contenido. La reinvención del espacio político hoy no pasa, pues, por demandas parciales, que a buen seguro el flexible pero ineluctable régimen libidinal de la desublimación represiva, con su instancia superyoica a gozar, no tardará en satisfacer. Régimen que, si secundamos ciertos diagnósticos del Marcuse de El hombre unidimensional, pivota en torno a tres rasgos específicos que nos dan una semblanza sorprendentemente vigente de la subjetividad neoliberal: satisfacción inmediata en detrimento de la mediatizada; absorción del principio de realidad por el del placer; y, por último, deserotización de toda energía libidinal independiente de la organización genital.

Es necesaria, contra tal adaptación autoinducida de la conciencia satisfecha, una exigencia radical de Universalidad que ponga en cuestión incondicionalmente que la única forma de vínculo social realmente vigente (no meramente tolerable) sea la subsunción real de la vida-trabajo en el Capital (con todas sus notas distintivas: plusvalía relativa, en vez de la absoluta propia de la subsunción formal, merced a la innovación tecnológica; conquista definitiva de todos los vestigios precapitalistas; tendencia a generar incesantemente nuevas ramas productivas, etc.), que ponga en cuestión esa servidumbre voluntaria ( sin coerción directa y con la representación ideológico-jurídica de consentimiento libre y consciente) de que se alimenta la "legitimidad" tardocapitalista. Es necesario un desencanto del poder sustancial del orden positivo del Ser como el que la Biblia introdujo en la legalidad "multiculturalista" del Imperio Romano, asentada en virtud de su excepcionalidad dictatorial, como se encargó de mostrar Ortega en sus lecciones sobre Toynbee, en la mayor ilegitimidad que la historia haya conocido.

\section{La revelación traumática del amor}

Žižek reactualiza el viejo quiasmo de Ernst Bloch: sólo un ateo puede ser un buen cristiano, sólo un cristiano puede ser un buen ateo. También la mordaz paradoja chestertoniana de que la gran locura de no ser cristiano resida justamente en no estar nada loco, en de "confiar totalmente en uno mismo", como nos dirían los gurús y personal trainers de hoy, todos ellos inmersos en la propaganda neognóstica de la autopurificación que caracteriza el resurgimiento tardocapitalista de la ética pagana (simbolizado exquisita y graciosamente en ese Padre Brown invertido que es el Kalon del relato "El ojo de Apolo").

$\mathrm{Y}$ es que no hay, como quiso Franz Rosenzweig en afinidad electiva con ciertas intuiciones freudianas, experiencias más radicales, experiencias que no pueden en modo alguno provenir de nosotros mismos, que las que se dan en el acontecimiento de la Revelación: la Palabra y el Amor como formas de perforar el narcisismo. Lacan, en el Seminario sobre El deseo y su interpretación, resalta dos aspectos del deseo que apuntan inequívocamente a esa dimensión de alteridad implicada en la Palabra y el Amor: por una parte, que la insubsumibilidad del discurso en la totalidad de una cadena de significantes, por mor del vacío que horada en la misma el significante tachado de la castración, permite que nos apercibamos de que lo que le falta al sujeto es lo que le permite identificarse como sujeto de su discurso; y, en segundo 
lugar, que la interpelación del Otro en la demanda carga a la demanda de una significación ("relación-de-amor") que excede la de la satisfacción de un besoin (aquí en divergente acuerdo con Lévinas y su distinción désir-besoin). Ello se debe a que el sujeto no puede situarse en el deseo sin perder lo esencial de su vida, el ágalma ${ }^{13}$.

Žižek plantea la experiencia del deseo como encuentro traumático con un Otro deseante (Dios como máximo acosador), cuya llamada externa da un vuelco a la inercia cotidiana de la seguridad narcisista al exponernos al enigma del goce del otro. Deseo y goce del Otro que constituyen la fibra íntima de la Revelación, y, por cierto, de la Revelación en tanto que kénosis (aprovecho para cuestionar cómo Žižek no puede rastrear esto hasta la Filosofía de la Revelación de Schelling, dejándola al margen como un repliegue a-dialéctico ante las tensiones generadas por las Weltalter), pues su terrible verdad hiperpascaliana "significa que Dios asumió el riesgo de jugárselo todo, de «comprometerse existencialmente» sin reservas, entrando, por así decirlo, en su propia obra, formando parte de la creación, exponiéndose a la contingencia radical de la existencia"14.

Acudiendo siempre a sus pasajes hegelianos predilectos (la noche vacía del Yo=Yo de la Fenomenología y el viernes santo especulativo de Fe y saber, entre otros), afirma Žižek que tal noción de la humillación divina es presupuesto del surgimiento de la subjetividad humana, singular y libre, esto es, según Hegel, la subjetividad moderna atea, condición sine qua non de la emergencia del Espíritu en toda su radicalidad protestante, del Espíritu en tanto que iglesia invisible, cuya invisibilidad obedece precisamente a la ausencia de toda comunión "naturalmente" identificable tras la muerte de Dios en la Cruz. Dicho psicoanalíticamente:

Este desplazamiento, este súbito reconocimiento de cómo el obstáculo mismo que nos impide alcanzar la Cosa misma nos permite identificarnos directamente con ella (con el punto muerto que hay en su centro) define la forma propiamente cristiana de identificación: en última instancia, se trata de la identificación con una falla $\mathrm{y}$, consecuentemente, puesto que el objeto de identificación es Dios, debe demostrarse que el mismo Dios falla ${ }^{15}$.

Ya Lacan había sentenciado en el seminario sobre La relación de objeto que el Espíritu Santo es "la entrada del significante en el mundo", y cuyo soporte es la pulsión de muerte en tanto que límite del significado nunca alcanzado, en tanto que "posibilidad de que nada de lo que hay en el significado exista"". La falta de objeto, al ser estructurante del mundo humano como tal en su estadio narcisista de la imagen especular, hace potencialmente universal el acceso al significante-Espíritu Santo, que sería, según Žižek en el pasaje citado, la forma de afrontar la falla, por así decirlo, honestamente, identificándose con ella e introyectándola, y no evadiéndola mediante una identificación con objeto arbitraria, que no sería sino un modo de prolongar subrepticiamente el estadio narcisista. Algo así se nos antoja que estaba pensando también Kierkegaard al escribir sus Obras del amor, donde recalca la

Cf. J. Lacan, Séminaire. Livre VI. Le désir et son interprétation, París, Ed. La Martinière, Le Champ Freudien, 2013, pp. 435-441.

14 S. Žižek y B. Gunjevic, El dolor de Dios, Madrid, Akal, 2013, p. 34.

15 S. Žižek, El titere y el enano, Madrid, Akal, 2010, p. 126.

16 J. Lacan, Seminario IV. La relación de objeto, Barcelona, Paidós, 1994, p. 53. 
intrincada complejidad del amor al prójimo, siempre en peligro de deslizarse a un amor de sí en el prójimo. Por el contrario, como gusta de citar repetidamente Žižek, el verdadero amor al prójimo, al estar mediado incondicionalmente por el amor de Dios, por la hiancia constitutiva del amor (no siendo el prójimo precisamente sino ese vacío, esa oquedad que opera en mí el deseo y que me divide), puede tornarse en un odio al prójimo por amor, en una violencia por despertarle de su alucinación narcisista.

En tal honestidad reside nada más y nada menos que la paradójica esencia de la libertad humana, de vocación radicalmente democrática. Entroncando con la chestertoniana "democracia de la muerte", afirma el grandísimo jurista e historiador E. Rosenstock-Huessy que "la libertad no es sino la introducción de la muerte en nuestras vidas. [...] La así llamada historia universal se hizo realidad desde el momento en que Todas las Almas [alusión a la festividad del primero de noviembre] comenzó a operar en cada hombre. [...] Anticipando las lecciones de la muerte, Europa aprendió la democracia, aprendió la Unidad, y aprendió la Universalidad" ${ }^{17}$.

Mas, si la identificación con la falla es la nota común al Dios de ambos Testamentos, ¿dónde situar la divergencia? Žižek pergeña al respecto una teoría, aunque novedosa en su acuñación lacaniana, coincidente por completo con la visión ortodoxa desde Orígenes y Agustín sobre la relación ambivalente (continuidad y ruptura) entre judaísmo y cristianismo, centrada en la paralaje paulina sobre la Ley. La continuidad reposa en que es en la experiencia bíblica donde se inicia el encuentro traumático externo del que hablamos arriba. Lo que sucede (siempre según Žižek, aunque yo tendería a hablar más bien, con Weber y Freud, de sublimación) es que el judío reprime el impacto proveniente de la imposibilidad del acceso a la Cosa misma, no confesando (simbolizando) la impotencia del Otro, sin caer, no obstante, en un relato fantasmático mítico-compensatorio. El sometimiento tenaz a la Torah-Superyó es justamente muestra de la fidelidad judía a la negación del violento Acontecimiento originario (asesinato de Moisés en la versión freudiana) y, a la vez, la preservación de la espectralidad que asedia el orden legal comunitario.

En este sentido, el Antiguo Testamento sería también una historia de la humillación de Dios: "la espectral narrativa judía negada no cuenta la obscena historia de la omnipotencia impenetrable de Dios, sino exactamente lo contrario: la historia de $\mathrm{Su}$ IMPOTENCIA encubierta por los complementos obscenos paganos corrientes. El secreto al que los judíos permanecen fieles es el horror de la impotencia divina y ESTE secreto es lo que se «revela» en el cristianismo"18. Es por ello que Freud es un perfecto judío al considerar en el prólogo a la $2^{\mathrm{a}}$ edición de la Traumdeutung que la muerte del Padre es el más relevante acontecimiento en la vida de un hombre. Según Hans Blumenberg, la torsión cristiana consistiría en que la muerte del Unigénito sea también el más relevante acontecimiento en la vida del Padre. El trabajo de duelo, por tanto, se halla presente biyectivamente en el conflicto Padre-Hijo, el cual, lejos de terminar con la muerte del Padre, como onto- y filogenéticamente todos sabemos, da comienzo con ella. La exclusión del Padre del campo de la experiencia constriñe al Hijo a su propia incursión en todas las fases y estadios del camino vital que antes contemplaba como desde la lejanía, protagonizado por un extraño, extraño que ha pasado a ser Él mismo ${ }^{19}$.

\footnotetext{
E. Rosenstock-Huessy, Out of revolution, Oxford, Berg, p. 513.

S. Žižek, El titere y el enano, op.cit., p. 176.

9 Cf. H. Blumengerg, Matthäuspassion, Frankfurt, Suhrkamp, 2012, p. 250.
} 
Las consecuencias que Pablo extrae de este desdoblamiento de la vida y la muerte divinas son de una eficacia histórica sin par. Consciente de cómo la Ley, al generar la transgresión, introduce la muerte en el mundo, y de que el pueblo que vive bajo tal experiencia de la opacidad del deseo del Otro ha de sustraerse necesariamente del conglomerado de los ethne asentados sobre sus regresiones narcisistas, Pablo no hace sino llevar la residualidad metahistórica del pueblo judío a su extremo: hace estallar por completo toda identidad sustancial (comunitarista, podríamos decir), incluso la de aquellos que hicieron estallar las identidades de todos los demás. Lo que Žižek llama la "transustanciación paulina del Pueblo Elegido" no es sino este tour de force de exceder la lógica judía del resto mediante la constitución de un resto del resto, que por no tener no tiene ni nombre. En efecto, la palabra "cristiano" no la conoce Pablo, más dialéctico que todos sus sucesores.

Pablo habla en todo caso de un "Israel de Dios" o de un "Pan-Israel" que será salvo cuando entren todas las gentes, y al que accede todo aquel que profesa la fe en la muerte y resurrección de Jesucristo en tanto que Kyrios, Acontecimiento que libera de la culpa hiperbólica e inexpiable (la Ley ciertamente es de Dios, pero no se puede cumplir íntegramente, se nos dice en ese psicoanálisis avant la lettre que es la Carta a los Romanos) de... haber matado al Padre, tal como han leído a Pablo un Nietzsche y un Freud. Mas Pablo, pese a sus rasgos gnósticos (los obstáculos cósmicos que hacen resistencia a la Redención, esos ciertos "arcontes" enigmáticos que gobiernan el mundo) se toma muy en serio la elección de Israel y opera con procedimientos plenamente judíos, erigiéndose, como apuntó Jacob Taubes siguiendo a Freud, en una suerte de Moisés radical, de amplificador de la culpa parricida hasta el paroxismo. La ira de Dios, tan veterotestamentaria, es, pues, elemento central de la dislocación paulina. Nada menos que el pecado hereditario fue lo que Pablo interpretó como castigo por el asesinato del Padre, de modo que ya sólo Dios mismo, "en forma de siervo", podía deshacer el entuerto.

Dejando constancia de tal aporía, no suficientemente atendida por Žižek, más preocupado de levantar acta de la ruptura con el judaísmo (si bien reconociendo, en plena ortodoxia, su imprescindible función pedagógica), detengámonos en el modo en que Pablo ejecuta su universalización del Pueblo de Dios. Para Žižek la clave está en cómo el ágape, al constituir un colectivo de quienes, por la fe en común, consienten en participar de la autoexposición y el autovaciamiento divinos (cuyo clímax es sin duda el lammá azabthani de la Cruz, tomado de un Salmo y ciertamente muy en la vena desafiante de Job), desborda el círculo del intercambio simbólico de la ley y el pecado. Así hay que entender el no ser uno mismo el que vive, sino Cristo en nosotros: como lectura participativa que implica compartir la muerte de Cristo en toda su intolerabilidad. Que la caridad sea el "fin de la ley" quiere decir precisamente eso: que el amor se hace una como Ley que se revoca a sí misma, que se excede a sí misma, suspendiendo la carga libidinal por la que la Ley incita a su propia transgresión.

Lacan reflexiona con su acostumbrada y sorprendente perspicacia en La ética del psicoanálisis sobre la paradoja del goce y la muerte de Dios:

Observemos que sólo el cristianismo da su pleno contenido, representado por el drama de la Pasión, a la naturalidad de esa verdad que llamamos la muerte de Dios. [...] El cristianismo propone un drama que encarna literalmente esa muerte de Dios. El cristianismo también vuelve a esa muerte solidaria de lo sucedido en lo concerniente a la Ley, a saber, que sin destruir, se nos dice, esa Ley, sino susti- 
tuyéndose a ella, resumiéndola, retomándola en el movimiento mismo en que la anula-Aufhebung-katargein etc...- el único mandamiento es desde entonces el Tú amarás a tu prójimo como a ti mismo.

[...] [U]na vez entrado en esa vía, una vez esbozado ese proceso, ya no hay límite - engendra una agresión cada vez más intensa contra el yo. La engendra en el límite, a saber, en tanto la mediación de la Ley falta. De la Ley en la medida en que ella provendría de otra parte- pero de esa otra parte en la que falta su garante, aquel que la garantiza, a saber, Dios mismo ${ }^{20}$.

Aunque más que del problema económico del masoquismo se trata aquí del amor al otro en lo Real, más allá del narcisismo abolido por la Ley y de la propia Ley en tanto que Simbólico. En definitiva: un amor al otro en el abismo de la ausencia del Gran Otro. Lo explosivo del proyecto mesiánico de Pablo radica en que, al asumir abiertamente la autoexinanición de Dios, llega a una noción de universalidad concreta que no se define por oposición a su otro, lo particular, sino diferenciándose de sí misma. Es así que la imposible identidad que diseña Pablo lo transforma todo dejándolo como está. El pathos de la distancia que introduce (I Corintios 7: "el que llora como si no llorase", etc.), lejos de reeditar la apatía estoico-gnóstico-oriental que en cierto modo persiste en Nietzsche, es el más abrupto efecto de la "universalidad en lucha" que propugna. Es, como dice Žižek, la distancia "de un luchador plenamente comprometido que ignora las distinciones ajenas a la lucha misma" ${ }^{21}$. ¿Y cuáles son esas distinciones ajenas a la lucha? Pues lisa y llanamente todas aquellas que no afecten a la vida de Cristo en mí, esto es, a la caridad, única dimensión universal por la que merece la pena luchar y, como bien vio Kierkegaard, hasta hacerse odioso al prójimo. De ahí lo que Žižek llama "desconexión cristiana", puesta entre paréntesis del orden vigente en que ha de vivir el Pueblo de Dios. En este punto es donde dio todos sus frutos la revolución total del judaísmo que Flavio Josefo nombró como teocracia: la relativización (por toma de distancia, sin interferencias ni insurgimientos; así hay que entender aquello del "todo me está permitido, mas no todo conviene", anticipada refutación paulina de Dostoyevsky) de todo poder fáctico en aras de la justicia de Dios, mas de un Dios ausente. Así pues, teocracia nada tiene que ver con el dominio de cualesquiera castas sacerdotales legitimadas por mediaciones sacramentales, y esto tendría que tenerlo bien cuenta la Iglesia Católica: el vicarius Dei es vicario de una falla, si es que no ha de recaer en el narcisismo de la deificación imperial. Justicia divina que, además, es la única en torno a la cual se congrega el pueblo sinceramente (cf., pues, cuán antiguo es el problema del marranismo), confiado para más inri en que será la que reine al final.

Ha de detectarse en Pablo una prolongación, incluso agudizada, de tal subversión teocrática del orden social, pues tan radical Umwertung comprende también, como apuntamos antes, al judío en tanto que perteneciente visiblemente al mismo. Recuérdese: hay que ser, para Pablo, judío "en lo oculto", a lo marrano. Sólo así cabe enfrentarse a las fuerzas del Imperio, como expresa Jacob Taubes con notable vehemencia:

El imperator no es el nomos, sino el clavado por el nomos a la cruz. Es una enormidad en cuya comparación son nada todos los aprendices de revolucionario. Esta

J. Lacan, Seminario. Libro VII. La ética del psicoanálisis, Buenos Aires, Paidós, 1997, pp. 233-235.

S. Žižek, El titere y el enano, op. cit., p. 153. 
inversión de los valores pone patas arriba la teología judeo-romano-helenística de las altas esferas, o sea, toda esa mezcolanza que llamamos helenismo. Cierto que Pablo sigue siendo universal, pero lo es por el ojo de la aguja del Crucificado, lo que quiere decir: la inversión de todos los valores de este mundo ${ }^{22}$.

La lógica circular expiatoria que busca a toda costa el restablecimiento simbólico se ve, pues, interrumpida por la inversión paulina, dando lugar no tanto a un apartamiento del orden concreto en que hayamos nacido cuanto a la creación de una "comunidad alternativa" superpuesta a éste, o, mejor, diluida a su través, minándolo desde dentro ${ }^{23}$.

Para concluir delimitaremos los contornos que puede adoptar esa comunidad alternativa en el horizonte tan difuso del capitalismo tardío, al cual podemos definir como el estadio de la evolución del Capital en que su violencia inherente se implementa sistémicamente, esto es, con independencia de cualesquiera acciones sociales concretas sobre vestigios pre-capitalistas; o, dicho de otro modo, inmersa de lleno en el estadio de la subsunción real ${ }^{24}$. Se trataría, como pronosticó Schumpeter recogiendo el testigo weberiano, de un capitalismo tras el carisma, tras la iniciativa creadora del emprendedor que canalizaba las energías liberadas por la ascesis intramundana (capitalismo de cuya pervivencia, por cierto, él, experto economista, albergaba serias dudas).

Ahora bien, si de Marx hemos de poder extraer una intelección correcta y aún válida del capitalismo, han de poderse constatar en su obra coordenadas teóricas que nos permitan acceder a tal implementación sistémica más allá del carisma merced a la cual el capitalismo modula la textura más íntima de nuestras vidas impersonal y objetivamente. Al respecto nos dice Lacan que ya la esencia inaugural del Capital y no meramente su fase tardía, ateniéndonos estrictamente a la letra marxiana, nada tiene que ver ni con el trabajo (hecho hoy palpable con el incremento exponencial del desempleo) ni con la renuncia al goce (hecho hoy palpable con la ya mentada desublimación represiva), sino, más bien, con que haya un discurso que articule tal renuncia, discurso al que él llama plus-de-goce ${ }^{25}$. La relación capitalista en cuanto efecto del discurso pertenece al campo del saber, y su verdad, en plena correspondencia con la unificación de la ciencia (aquí se insinúa el Lacan heideggeriano), cristaliza en la cuantificación, en el número, en el precio de la mercancía; saber éste que deviene término opaco en el que el sujeto viene a perderse y a extinguirse a sí mismo. Ya hemos hablado de todo esto a colación de la ideología, de modo que no nos demoramos más en ello.

El desplazamiento del valor de uso al valor de cambio impulsado por la producción de plusvalía, con la erradicación del medio de producción de su estar al servicio de la satisfacción (contra el hedonismo de todas las éticas premodernas), encaja a la perfección con el descubrimiento freudiano del sujeto (moderno-capitalista) debatido entre la pérdida del goce y las prácticas incesantes de su recuperación (el Wiederholungszwang tan propio del carácter anal como del éthos capitalista). El goce que en la dialéctica hegeliana era dejado por el amo al esclavo (a quien le sustrae, en

\footnotetext{
J. Taubes, La teología política de Pablo, Madrid, Trotta, 2007, p. 39.

Cf. S. Žižek, El frágil absoluto, Valencia, Pre-textos, 2002, p. 168.

Cf. Ibidem, p. 25.

Cf. J. Lacan, Séminaire. Livre XVI. D'un Autre à l'autre, Paris, Seuil, 2006, pp. 16 y ss.
} 
cambio, el saber) se transmuta, mediante la "liberación" del esclavo, en su encadenamiento al plus-de-goce y a la totalización del saber.

Pues bien, por un giro inesperado con el que retornamos a anteriores aspectos de nuestra exposición, en el seminario recién citado Lacan nos invita a examinar la apuesta de Pascal como punto de inflexión en la conceptualización del plus-degoce $^{26}$. Pascal, marcado por la herida agustiniana (tan paulina en el fondo) del jansenismo y de la gracia como deseo del Otro, llegó a hacer una experiencia radical del campo del Otro como lugar de la palabra, o, dicho menos crípticamente, de la escisión del yo del saber y del yo del goce, que el discurso capitalista busca solapar subrepticiamente en larvada afinidad electiva nada menos que con toda la tradición del argumento ontológico, como insinuamos arriba. El Dios de Pascal es la incidencia del significante, el Dios que habla, el Dios de la Revelación como dimensión portadora de verdad más allá del campo del saber. Sólo así se abandona el plano imaginario-narcisista del Dios de los filósofos, el Uno, gran Otro que sostiene el sistema simbólico capitalista, en cuyas redes se enmaraña el plus-de-goce, el sujet supposé savoir que Lacan adscribe, según Žižek erróneamente, al saber absoluto hegeliano.

Así pues, nos enfrentamos a un curioso quiasmo: la emergencia del saber supone la exclusión del goce, pero el goce no deja de ser lo real último del funcionamiento del sistema que lo excluye. Del mismo modo sucede en el capitalismo: el goce, excluido del trabajo, le da a éste todo su real.

La "revolución" no sería sino el colapso de tal aporía, evidentemente ausente del contexto antiguo (puede mencionarse aquí la teoría de las revoluciones de Rosenstock-Huessy, que se inicia con el pontificado de Gregorio VII en el cambio de milenio), y de cuya eficacia histórica Lacan parece desentenderse con irónica distancia. No así Žižek, que, partiendo de la inasumibilidad del goce por el saber que Lacan descifra en Pascal, aplica tal negatividad radical, como se desprende de nuestra lectura de su Pablo, a la conformación de un sujeto político que no consista justamente en el agotamiento recursivo del deseo en la espiral del plus-de-goce, sino que se constituya en su propia metaforicidad inenglobable en la totalización del saber, siempre remitiendo a su exceso, a su afuera, pues todo deseo, para ser tal, es literalmente deseo del Infinito, como quisieron Lévinas y Lacan. Ello conmina al sujeto a horadar el espacio social autoescindiéndose para que éste se constituya ${ }^{27}$. Es ésta la dimensión contingente (incontrolable, imprevisible, etc.) de la verdad más allá del saber que, como el Logos joánico, se hace carne, se hace praxis universal en el encuentro traumático con lo Real, uno de cuyos más impactantes testimonios acaso nos legó Pascal cosido en su hábito en el instante de su muerte.

Así es como Žižek puede llegar a definir la izquierda como un compromiso con el deseo como imposibilidad traumática, como falla constitutiva inasimilable. El sujeto político, afrontando su deseo, asume el riesgo (pues eso es lo que es, como nos enseña Pascal) de no ceder ante su engaño narcisista y su manipulación fetichista. Y así como la imposible comunidad que Pablo quiso crear se vinculaba mirando al futuro en la rememoración insistente del mayor trauma imaginable, transfigurándose

\footnotetext{
26 Sobre Pascal como reverso en negativo de la "imagen burguesa del mundo" consúltense los capítulos a él consagrados de la tan penetrante como desatendida obra de Franz Borkenau Der Übergang vom feudalen zum bürgerlichen Weltbild.

27 Cf. S. Žižek, Porque no saben lo que hacen, Barcelona, Paidós, 1998, pp. 254-255.
} 
en el vuelco que el kairós imprimía al orden fáctico, del mismo modo Žižek exhorta a que la izquierda

debe preservar las huellas de todos los traumas, sueños y catástrofes históricos que la ideología imperante del "fin de la historia" preferiría obliterar; debe convertirse a sí misma en su monumento vivo, de modo que, mientras esté la izquierda, esos traumas sigan marcados. Esta actitud, lejos de confinar a la izquierda a un enamoramiento nostálgico del pasado, es la única posible para tomar distancia sobre el presente, una distancia que nos permita discernir los signos de lo Nuevo ${ }^{28}$. 